\title{
Pengelolaan Limbah Pertanian dan Rumah Tangga Berbasis Masyarakat di Desa Nglegi Patuk Gunungkidul, Yogyakarta
}

\author{
Surahma Asti Mulasari ${ }^{1}$ \\ ${ }^{1}$ Universitas Ahmad Dahlan
}

\begin{tabular}{|c|c|}
\hline ARTICLE INFO & ABSTRACT \\
\hline $\begin{array}{l}\text { Article History: } \\
\text { Received 05.07.2018 } \\
\text { Received in revised } \\
\text { form 09.11.2018 } \\
\text { Accepted 23.11.2018 } \\
\text { Available online } \\
\text { 03.12.2018 }\end{array}$ & $\begin{array}{l}\text { This program focusses on particular issues in Nglegi Patuk Gunung Kidul } \\
\text { that is the abundance of agricultural waste, the large number of household } \\
\text { waste that does not proceed correctly. The purpose of this activity was to } \\
\text { increase community participation in processing domestic waste. The training } \\
\text { participants were PKK villages from Nglegi Village. This program offered } \\
\text { how to proceed the household waste with the 3R (Reuse, Reduce, Recycle) } \\
\text { method. This activity conducted through lecture and demonstration on } \\
\text { household and agricultural waste processing. The results of this activity were } \\
\text { this program can improve the community knowledge and expected can } \\
\text { change the community behavior. }\end{array}$ \\
\hline & Keywords: Agriculture, Household, Waste. \\
\hline
\end{tabular}

DOI: $10.30653 / 002.201832 .52$

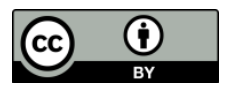

This is an open access article distributed under the terms of the Creative Commons Attribution 4.0 International License, which permits unrestricted use distribution, and reproduction in any medium, provided the original work is properly cited. @ 2018 Surahma Asti Mulasari.

\section{PENDAHULUAN}

UU No. 18/2008 tentang Pengelolaan Sampah mendorong adanya suatu usaha pengelolaan sampah yang dilakukan dengan maksimal. Adapun upaya pengelolaan sampah dapat dilakukan dengan cara Reuse, Reduce, dan Recycle (3R) adalah kegiatan memperlakukan sampah dengan cara, menggunakan kembali (reuse), mengurangi (reduce) dan mendaur ulang (recycle).

Demikian pula di tingkat desa, perlu adanya aktivitas untuk melakukan pengelolaan sampah rumah tangga yang dihasilkannya. Mitra dalam kegiatan pengabdian ini adalah Desa Nglegi Patuk Gunungkidul. Permasalahan mitra di Desa Nglegi adalah banyaknya limbah pertanian dari aktivitas pertanian palawija dan persawahan. Pertanian palawija seperti ladang kacang, kedelai, dan kebun kakao, namun pada daerah yang jauh dari rumah penduduk mayoritas ditanami pohon jati. Komoditas tanaman yang ditanam di sawah adalah padi. Semua jenis pertanian tersebut menghasilkan limbah pertanian.

Permasalahan lain adalah di Desa Nglegi jumlah penduduk ada 3.225 orang dengan jumlah KK 871 KK. Banyaknya jumlah penduduk berpotensi untuk menghasilkan limbah

${ }^{1}$ Corresponding author: Fakultas Kesehatan Masyarakat, Universitas Ahmad Dahlan; Jl. Prof. Dr. Soepomo, Warungboto, Umbulharjo, Kota Yogyakarta 55164. Email: surahma.mulasari@ikm.uad.ac.id 
domestik rumah tangga. Pengolahan sampah saat ini masih sebatas dikubur dan dibakar. Berdasarkan penelitian yang dilakukan oleh Riswan dkk (2011), timbunan sampah ratarata tiap rumah tangga sebesar 1,46 liter/orang/hari atau 0,38 kg/orang/hari, setara dengan kategori SNI 19-3964-1994 untuk satuan timbulan sampah kota sedang/kecil. Dari hasil penelitian tersebut, apabila digunakan untuk memprediksi timbulan sampah berdasar jumlah penduduk di Desa Nglegi, akan diperoleh volume sampah yang cukup banyak yaitu sebesar $4.708,5$ liter atau $1.225 .500 \mathrm{~kg}$ per hari. Potensi sampah ini beresiko untuk mencemari lingkungan di wilayah desa Ngegi dan sekitarnya. Untuk mengatasi permasalahan yang ditimbulkan oleh banyaknya volume sampah tersebut, dibutuhkan solusi yang tepat dan sekaligus dapat dilaksankanan oleh masyarakan di sana.

Solusi yang ditawarkan dalam kegiatan pengabdian masyarakat ini adalah pengelolaan sampah rumah tangga dengan metode $3 \mathrm{R}$ yaitu reduce, reuse, dan recycle. Potensi yang dimiliki masyarakat di lokasi pengabdian berupa banyak lahan kosong di lokasi pengabdian yang dapat dimanfaatkan untuk kegiatan pengelolaan sampah yang terintergrasi dengan tamanisasi atau pertanian di lahan pekarangan. Selain itu, tanah di daerah ini tergolong tanah subur. Sinergi antara lahan kosong dan suburnya tanah dapat digunakan untuk membangun pertanian atau perkebunan di lahan pekarangan. Aktivitas ini ditunjang dengan pemanfaatan sampah rumah tangga dan tanaman menjadi kompos. Sehingga keberlanjutan program pengolahan sampah dan limbah pertanian dan domestik rumah tangga tersebut dapat dimanfaatkan untuk pertanian lahan pekarangan. Harapannya solusi yang ditawarkan tersebut dapat mengatasi banyaknya timbulan sampah dan ancaman pencemaran lingkungan akibat sampah.

Pengelololaan sampah merupakan salah satu konsep yang dapat membantu mengatasi dampak timbulan sampah. Salah satu cara untuk meningkatkan kesadaran masyarakat mengelola sampah adalah dengan meningkatkan aspek kognitifnya yaitu pengetahuan masyarakat tentang mengelola sampah (Sari \& Mulasari, 2017). Tujuan kegiatan pengabdian ini adalah untuk memberikan wawasan dan edukasi kepada masyarakat khususnya ibu-ibu rumah tangga tentang pemahaman pengolahan sampah dengan memanfaatkan sampah rumah tangga atau sampah yang dihasilkan dari kegiatan dalam rumah tangga. Kemudian para ibu-ibu dapat memberikan edukasi sejak dini kepada anggota rumah tangga, termasuk anak-anak, sehingga tertanam rasa kepedulian mereka akan pentingnya menjaga kebersihan rumah dan lingkungan, dapat bersahabat dengan lingkungan, yang kemudian dapat mengolah sampah dengan mendaur ulang sampah dan mengasilkan sesuatu dari sampah tersebut.

\section{METODE PELAKSANAAN}

Solusi yang ditawarkan dalam program pengabdian ini adalah "Pelatihan Pengolahan Sampah Rumah Tangga \& Limbah Pertanian". Apabila digambarkan sinergi antara permasalahan, potensi, dan solusi yang ditawarkan dapat dilihat dari Gambar 1.

Permasalahan di lokasi berupa banyaknya sampah domestik rumah tangga dan limbah pertanian di lokasi pengabdian dan apabila dilihat dari sudut pandang yang berbeda dapat dipandang sebagai potensi untuk menjamin keberlangsungan program. Solusi yang ditawarkan, dan dengan mempertimbangkan potensi yang ada, memastikan program "pengelolaan sampah domestik rumah tangga dan limbah pertanian" tepat dilakukan dan akan mendukung potensi pemanfaatan lahan pekarangan menjadi lahan pertanian lahan kering, sekaligus memastikan bahwa program tersebut dapat berkelanjutan. 


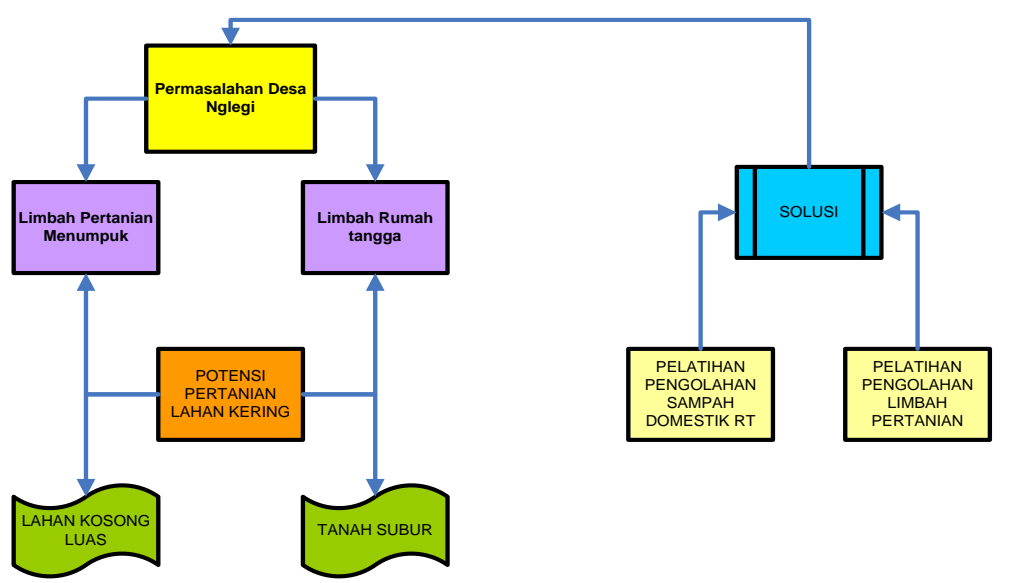

Gambar 1. Hubungan antara permasalahan, potensi, dan solusi yang ditawarkan PPM

Materi yang diberikan berupa materi ceramah dan pelatihan, sehingga peserta tidak hanya mendengarkan ceramah tetapi juga mendapatkan pelatiahan dan contoh. Materi yang disajikan berkaitan dengan pelatihan pengolahan sampah meliputi definisi, maksud dan tujuan, manfaat yang dihasilkan, jenis sampah, macam-macam bentuk pengolahan sampah. Tidak hanya itu, peserta juga disajikan materi dengan membagikan brosur mengenai swakelola agar peserta pelatihan dapat lebih meningkatkan kemampuan dalam menyerap materi yang disampaikan oleh narasumber, selain itu peserta dapat membaca kembali materi pelatihan di rumah, apabila peserta pelatihan ada yang lupa mengenai materi pelatihan yang sudah disampaikan sebelumnya.

Dengan adanya pelatihan, besar harapannya ibu-ibu dapat memiliki pengetahuan tentang pengolahan sampah dengan memanfaatkan sampah yang dihasilkan dari aktivitas rumah tangga sekaligus selanjutnya dapat mengedukasi anggota rumah tangga terutama anak-anak untuk menjaga kebersihan rumah dan lingkungan dengan tidak mencemarinya dengan sampah yang dihasilkan dari aktivitas rumah tangga tersebut. Tidak hanya itu, selain ceramah dan pelatihan, metode yang dilakukan juga diselingi dengan diskusi dan tanya jawab sebagai bentuk timbal balik agar tidak terkesan monoton. Pada kesempatan ini peserta dapat mengeluarkan pertanyaan dan secara bersama mendiskusikan jawaban dari pertanyaan tersebut.

Metode lain yang dilakukan adalah dengan demonstrasi alat dan bahan secara langsung kemudian secara bersama-sama mencoba mengolah sampah tersebut menggunakan kerangjang Takakura untuk membuat kompos. Dengan demikian peserta tidak hanya mengetahui teori-teori yang ada, tetapi peserta langsung disajikan bahan ajar untuk memperkuat gambaran yang telah dipaparkan oleh narasumber.

Kegiatan pengabdian ini dilaksanakan hari Selasa, tanggal 06 Februari 2018, pada pukul 10.00 sampai dengan 14.00 WIB dan bertempatkan di Balai Desa Nglegi, Patuk, Gunung Kidul, Yogyakarta.

\section{HASIL DAN PEMBAHASAN}

Hasil observasi awal di Desa Nglegi menunjukkan bahwa beberapa tahun lalu telah ada sosialisasi pengelolaan sampah dengan bank sampah yang menekankan pengelolaan sampah dengan metode 3R. Akan tetapi program tersebut tidak berjalan dengan lancar dan mengalami fakum kegiatan. Penelitian Salawati, Astuti, dan Hayati (2010) mengatakan bahwa setelah satu bulan pelatihan pengetahuan responden mengenai mengolahan sampah mengalami penurunan. Menurut keterangan ketua penggerak PKK, penyebab 
utama kegiatan tidak berjalan disebabkan kurangnya antusias masyarakat dalam mengelola sampah. Hal tersebut kemungkinan karena kesibukan, kerumitan, dan komitmen pengurus. Kondisi masyarakat kurang antusias dalam mengelola sampah serupa dengan masyarakat di Kota Yogyakarta dimana perilaku masyarakat belum baik dalam mengelola sampah (Mulasari el al, 2016). Sikap masyarakat yang kurang antusias dalam mengolah sampah tidak hanya ditemukan di Indonesia. Di Nigeria, sikap acuh penduduk menjadi salah satu faktor penyumbang terhadap masalah pengolahan limbah (Fafioye \& Jhon-Dewole, 2013).

Brainstorming dengan warga pada saat penggalian masalah diperoleh fakta bahwa masyarakat masih kurang pengetahuan dan keterampilannya mengolah sampah rumah tangga dan limbah pertanian/pekarangan. Tingkat pengetahuan tentang pengelolaan sampah mempengaruhi perilaku pengelolaan sampah masyarakat (Susanto, el al, 2010). Pemahaman bahwa sampah/limbah memiliki nilai ekonomis juga belum dimiliki sebagian peserta. Peserta selama ini banyak yang tidak memiliki keinginan dan kesadaran untuk mengolah sampah. Sampah rumah tangga hanya dikubur atau dibakar. Masyarakat Desa Nglegi banyak yang belum mengetahui cara pengelolaan sampah yang aman bagi kesehatan dan lingkungan.

Permasalahan pengolahan sampah hanya dibakar juga terdapat di Dusun Padukuhan Desa Sidokarto Godean Sleman dimana masyarakat memilih pembakaran sampah yang sebetulnya kegiatan ini dapat menyebabkan gangguan kesehatan bagi masyarakat sendiri maupun merusak atau mencemari lingkungan (Mulasari, 2012). Di Abeokuta, Nigeria sebagian besar penduduk juga tidak melakukan pengolahan sampah dengan baik, sampah tidak dipisah, sampah dibuang ke lingkungan sekitar rumah, dan hanya sedikit penduduk yang melakukan daur ulang sampah (Achi et al., 2012).

Kondisi masih rendahnya pengetahuan sebagian peserta tentang manfaat ekonomi sampah/limbah di Desa Nglegi hampir sama dengan masyarakat di Sumberarum Sleman. Masyarakat petani di sana tidak mengolah sampah/limbah pertanian karena kurangnya motivasi berwirausaha produk hasil pengolahan limbah pertanian. Pelatihan motivasi berwirausaha limbah pertanian menjadi produk dapat meningkatkan motivasi masyarakat dalam mengelola limbah pertanian (Tentama et al., 2016). Kondisi di Desa Nglegi juga ditemukan di RW 12 Kelurahan Banguntapan Kecamatan Banguntapan Bantul. Kesadaran masyarakat di sana sulit untuk ditingkatkan karena masih banyak masyarakat yang beranggapan bahwa sampah dibakar atau dibuang itu tidak beresiko. Masyarakat di RW 12 Banguntapan Bantul tersebut menganggap mengelola sampah tidak ada manfaatnya (Sukesi el al, 2017).

Menurut Forouhar dan Hristovski (2012) permasalahan sampah memerlukan suatu manajemen yang tepat dalam pengelolaan sampah. Kusminah (2018) menyatakan bahwa pengelolaan sampah yang direncanakan dapat membantu masyarakat menyediakan lapangan pekerjaan sebagai petugas sampah dan juga akan mendatangkan pemasukan bagi warga karena semua sampah dimanfaatkan dengan baik dan bernilai guna serta pengelolaan tersebut dapat dijadikan contoh untuk diterapkan di daerah-daerah sekitar.

Metode yang digunakan untuk mengatasi permasalah di lokasi pengabdian adalah dengan metode ceramah dan pelatihan pengolahan sampah rumah tangga dan limbah pertanian/pekarangan. Pengolahan sampah adalah program mengenai macam-macam atau metode untuk mendaur ulang kembali sampah menjadi bentuk yang lain sehingga dapat dimanfaatkan dan bernilai ekonomis. Pelatihan pengolahan sampah diselenggarakan untuk menjawab dari permasalahan sampah yang dihasilkan oleh kegiatan-kegiatana dalam rumah tangga. Pelatihan pengolahan sampah merupakan salah 
satu upaya dalam rangka mewujudkan upaya pengurangan pencemaran lingkungan yang bernilai ekonomis. Hasil dari pelatihan adalah komposter model lindi dan pembuatan activator pengomposan dari bahan tempe, nanas, pisang, bawang merah dan air gula (Gambar 2).

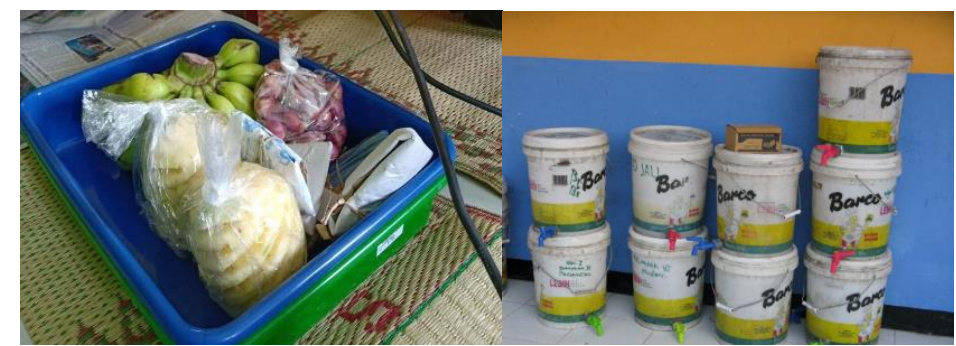

Gambar 2. Bahan pembuat activator pengomposan dan bak pengomposan

Metode ceramah dan pelatihan pengolahan sampah merupakan salah satu pendekatan masyarakat yang relevan. Pendekatan tersebut secara bertahap mampu mendorong masyarakat untuk bersedia terlibat, melakukan dan merasakan manfaat. Pendekatan partisipasi masyarakat juga mampu mendorong partisipasi masyarakat dalam pengelolaan sampah sejak dari sumbernya (Setiadi, 2015).

Pemilihan solusi dengan metode ceramah dan pelatihan diambil berdasarkan hasil penelitian sebelumnya yang menunjukkan bahwa hasil pelatihan pengolahan sampah rumah tangga dapat meningkatkan pengetahuan, perhatian, presepsi, perilaku dan resiko penularan vector penyakit akibat sampah (Mulasari et al, 2016). Penelitian lain yang sejalan menyatakan pelatihan pengolahan sampah terbukti meningkatkan ketrampilan pengetahuan dan pengolahan sampah (Salawati, el al, 2008). Hasil dari kegiatan ini adalah:

1) Memberikan edukasi tentang pengolahan sampah kepada masyarakat terutama ibuibu rumah tangga dengan cara pelatihan pengolahan sampah.

2) Membangun kesadaran dan tanggung jawab bersama dalam pengendalian pencemaran lingkungan yang diakibatkan dari adanya sampah rumah tangga.

3) Untuk melatih dan membekali ibu-ibu rumah tangga menumbuhkan komitmen dan tanggung jawab.

4) Meningkatkan kapasitas dalam mengelola dan memanfaatkan sampah rumah tangga dalam rangka gerakan pengurangan pencemaran lingkungan.

5) Menjadikan sampah sebagai sumber pembelajaran inovatif dan memanfaatkan sampah untuk ekonomi kreatif.

6) Tidak adanya kerusakan lingkungan.

7) Lingkungan sekitar menjadi bersih dan bebas dari bahan pencemar.

\section{SIMPULAN}

Melalui kegiatan pengabdian ini, peserta mengetahui dan memahami tentang pengolahan sampah rumah tangga, selain itu masyarakat dapat mengaplikasikannya di rumah masing-masing, serta memberikan alternatif pengolahan dan pengembangan sampah rumah tangga. Hasil pengabdian menyarankan kepada peserta (ibu-ibu rumah tangga) agar dapat memanfaatkan sampah rumah tangga dan dapat mengedukasi anggota rumah tangga untuk menjaga kebersihan lingkungan dengan mengolah sampah rumah tangganya sendiri sehingga terwujud kesehatan dan kebersihan lingkungan yang bernilai ekonomis. 


\section{REFERENSI}

Achi, H. A., Adeofun, C. O., Gbadebo, A. M., Ufoegbune, G. C., \& Oyedepo, J. A. (2012). An assessment of solid waste management practices in Abeokuta, South West Nigeria. Journal of Biological and Chemical Research, 29(2), 177-188.

Fafioye, O. O., \& John-Dewole, O. O. (2013). A critical assessment of waste management problems in ibadan south-west local government area, Ibadan, Nigeria. Greener Journal of Environmental and Management Studies, 2(2), 60-64.

Forouhar, A., \& Hristovski, K. D. (2012). Characterization of the municipal solid waste stream in Kabul, Afghanistan. Habitat International, 36(3), 406-413.

Kusminah, I. L. (2018). Penyuluhan 4r (reduce, reuse, recycle, replace) dan kegunaan bank sampah sebagai langkah menciptakan lingkungan yang bersih dan ekonomis di desa Mojowuku Kab. Gresik. JPM17: Jurnal Pengabdian Masyarakat, 3(1), 22-28.

Mulasari, S. A. (2013). Hubungan tingkat pengetahuan dan sikap terhadap perilaku masyarakat dalam mengolah sampah di Dusun Padukuhan Desa Sidokarto Kecamatan Godean Kabupaten Sleman Yogyakarta. Jurnal Kesehatan Masyarakat (Journal of Public Health), 6(3). 204-211.

Mulasari, S. A., Husodo, A. H., \& Muhadjir, N. (2016). The effectiveness of health-communitybased waste management in Yogyakarta. International Journal of Indonesian Society and Culture, 8(1), 51-58.

Mulasari, S. A., Husodo, A. H., \& Muhadjir, N. (2016). Analisis situasi permasalahan sampah kota Yogyakarta dan kebijakan penanggulangannya. Jurnal Kesehatan Masyarakat, 11(2), 259-269.

Riswan, R., Sunoko, H. R., \& Hadiyarto, A. (2011). Pengelolaan sampah rumah tangga di Kecamatan Daha Selatan. Jurnal Ilmu Lingkungan, 9(1), 31-38.

Salawati, T., Astuti, R., \& Hayati, R. N. (2008). Pengaruh program pelatihan pengolahan sampah padat organik menggunakan metode composting terhadap pengetahuan dan ketrampilan ibu-ibu PKK di RW III Kelurahan Boja Kabupaten Kendal. Jurnal Promosi Kesehatan Indonesia, 3(2), 63-73.

Sari, N., \& Mulasari, S. A. (2017). Pengetahuan, sikap dan pendidikan dengan perilaku pengelolaan sampah di Kelurahan Bener Kecamatan Tegalrejo Yogyakarta. Jurnal Medika Respati, 12(2), 74-84.

Setiadi, A. (2015). Studi pengelolaan sampah berbasis komunitas pada kawasan permukiman perkotaan di Yogyakarta. Jurnal Wilayah dan Lingkungan, 3(1), 27-38.

Sukesi, T.W., Mulasari, S. A., Sulistyawati, \& Tentama, F., (2017). Pemberdayaan masyarakat dalam pengelolaan sampah rumah tangga. Prosiding Seminar Nasional Hasil Pengabdian Membangun Desa untuk Indonesia Berkemajuan. Universitas Ahmad Dahlan, October 25 th 2017 (pp. 135-141). Yogyakarta: UAD.

Susanto, R., \& Pahroni, R. (2010). Hubungan pengetahuan terhadap pengelolaan sampah Organik dan non organik pada masyarakat RW 03 Sumbersari Malang. Jurnal Keperawatan, 1(1), 32-38.

Tentama, F., Mulasari, S. A., \& Kusuma, D. R. (2016). Efficacy of enterpreneurship training on improving enterpreneurship motivation in the face of asean economic community (MEA), Proceeding Human Resource Improvement, in The Current ASEAN Economic Community (AEC) Through a Psychological Perspective. Muang, Songkhla, Thailand August 8th, 2016 (pp. 57-66).

Undang-Undang Republik Indonesia Nomor 18 Tahun 2008 Tentang Pengelolaan Sampah Sekolah. 